\title{
Understanding the true effects of the COVID-19 lockdown on air pollution by means of machine learning
}

\author{
Mario Lovrić ${ }^{1, *}$, Kristina Pavlović ${ }^{1}$, Matej Vuković ${ }^{2}$, Stuart K. Grange ${ }^{3,4}$, Michael \\ Haberl $^{5}$, Roman Kern ${ }^{1}$ \\ ${ }^{1}$ Know-Center, Inffeldgasse 13/6, AT-8010 Graz \\ ${ }^{2}$ Pro2Future, Inffeldgasse 25F, AT-8010 Graz \\ ${ }^{3}$ Empa, Swiss Federal Laboratories for Materials Science and Technology, 8600 Dübendorf, \\ Switzerland \\ ${ }^{4}$ Wolfson Atmospheric Chemistry Laboratories, University of York, York, YO10 5DD, United \\ Kingdom \\ ${ }^{5}$ Institute of Highway Engineering and Transport Planning, Rechbauerstraße 12, AT-8010 Graz
}

*Corresponding author: mlovric@know-center.at

Keywords: $\mathrm{PM}_{10}, \mathrm{NO}_{2}$, Total oxidant, $\mathrm{O}_{\mathrm{x}}, \mathrm{O}_{3}$, Random forest, Corona crisis
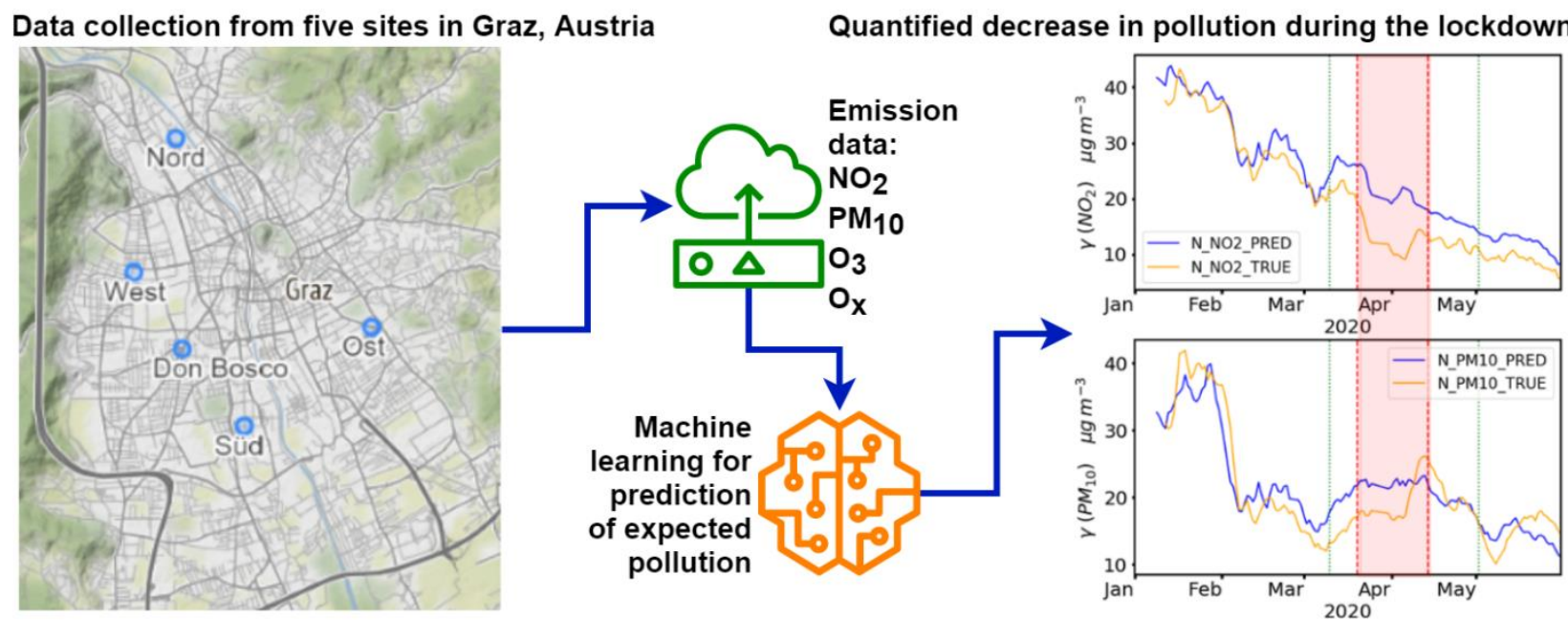

Graphical Abstract 


\begin{abstract}
During March, 2020, most European countries implemented lockdowns to restrict the transmission of SARS-CoV-2, the virus which causes COVID-19 through their populations. These restrictions had positive impacts for air quality due to a dramatic reduction of economic activity and emissions. In this work, a machine learning approach was designed and implemented to analyze local air quality improvements during the COVID-19 lockdown in Graz, Austria. The machine learning approach was used as a robust alternative to simple, historical measurement comparisons for various individual pollutants. Concentrations of $\mathrm{NO}_{2}$ (nitrogen dioxide), $\mathrm{PM}_{10}, \mathrm{O}_{3}$ (ozone) and $\mathrm{O}_{\mathrm{x}}$ (total oxidant) were selected from five measurement sites in Graz and were set as target variables for random forest regression models to predict their expected values during the city's lockdown period. The true vs. expected difference is presented here as an indicator of true pollution during the lockdown. The machine learning models showed a high level of generalization for predicting the concentrations. Therefore, the approach was suitable for analyzing reductions in pollution concentrations. Results on the validation set showed very good performance for $\mathrm{O}_{\mathrm{x}}$ and $\mathrm{NO}_{2}$ when compared to $\mathrm{PM}_{10}$ and $\mathrm{O}_{3}$. The analysis indicated that the city's average concentration reductions for the lockdown period were: -36.9 to $-41.6 \%$, and -6.6 to $-14.2 \%$ for $\mathrm{NO}_{2}$ and $\mathrm{PM}_{10}$, respectively. However, an increase of 11.6 to $33.8 \%$ for $\mathrm{O}_{3}$ was estimated. The reduction in pollutant concentration, especially $\mathrm{NO}_{2}$ can be explained by significant drops in traffic-flows during the lockdown period (51.6 to $-43.9 \%$ ). The results presented give a real-world example of what pollutant concentration reductions can be achieved by reducing traffic-flows and other economic activities.
\end{abstract}




\section{Introduction}

The COVID-19 pandemic has caused disastrous health and socio-economic crises across the globe [1], [2]. Questions have been raised whether atmospheric pollution is a co-factor in disease development causing a higher lethality rate, especially in highly populated and polluted areas such as those in Italy [3], [4]. A study from China suggests there is a statistically confirmed relationship between air pollution by means of elevated concentrations of $\mathrm{PM}_{2.5}, \mathrm{PM}_{10}, \mathrm{CO}, \mathrm{NO}_{2}$ and $\mathrm{O}_{3}$ and the COVID-19 infection rate [5]. An interplay of air quality and the pandemic seems obvious.

On the other side, lockdowns have caused significant changes in air quality [6]. A study on 44 Chinese cities [7] showed a decrease in main air pollutants from 5.93-24.67\% during the lockdown while megacities such as Sao Paulo showed even higher concentration drops (40-70\%) for some pollutants [8]. A study on $\mathrm{PM}_{2.5}$ in capital cities showed concentration drops of 20-60\% during the COVID-19 crisis [9]. It is suggested that the pollution drop was mainly driven by a reduction in traffic [10] and industrial activities [11]. Even if lockdowns hinder economic growth and might cause various negative effects in the long term, drops in pollution concentrations may act as another factor which slows disease transmission in tandem with limiting human contact. Lockdowns in Europe were instituted gradually by means of governmental interventions [12]. This massive intervention also poses a unique opportunity to study the change in various aspects of air quality, thus motivating our study.

We discuss and explore that for complete understanding of the true factors influencing pollutant concentrations, pure statistical tests or single-day comparisons might be inadequate since weather conditions, particle persistence and seasonality affect concentrations by linear and non-linear processes [13]. We investigate the effects of the gradually introduced lockdown on air quality in an urbanized area in Graz, Styria, Austria. Due to the high degree of traffic influence, we have included traffic data into our analysis. Furthermore, we have investigated in detail which of the pollutants' concentrations were more affected by the lockdown. We have employed machine learning to understand the true effects of the intervention measures and discern them from random and other factors [5], such as weather conditions. As such, the outcome of our study serves as a guide for future interventions and their expected associated change in the pollutants' concentration changes. 


\section{Materials and methods}

Our study contains traditional exploratory statistical analysis, such as principal component analysis (PCA) to explore the key attributes. In addition, the main analysis is based on machine learning models build to capture the historical relationships between the attributes and compare the predictions after the interventions took place. In particular, we utilize historical data which matches the time frame of the lockdown for the preceding years. We further include traffic data and present the drop in mobility. First, we present the data sources and the data cleaning and preprocessing procedures.

\section{Data}

We collected environmental, pollution and weather data from publicly available sources provided by the Austrian government ${ }^{1}$. To have a realistic picture of air quality during the lockdown, we analyzed long term measurement data from January 2014 to May 2020 from five measurement sites in the Austria city of Graz (Süd (eng. South) - S, Nord (eng. North) - N, West (eng. West) W, Don Bosco - D, Ost (eng. East) - O); Figure 1). The latter two sites are situated on arterial roads with high traffic volumes, especially during the morning and evening rush hours. The most polluted measurement site of Graz is Don Bosco that struggles to meet annual $\mathrm{NO}_{2}$ and $\mathrm{PM}_{10}$ regulatory limits of the EU-Council directive 96/62/EC. This is primarily because of traffic related emissions, but also because of emissions from a nearby steel- and iron-mill [14]. Although Graz East is located at a heavily frequented commuter-arterial the situation is not that severe. Graz South is situated at a secondary road segment but also records higher pollutant concentrations due to an industrial complex nearby. Graz North and West are classed as urban background sites and are located near to minor roads with no specific emission contributors in immediate vicinity. A more detailed site description, photos of the sites and historical overview of the sites is given in Moser et al., 2019.

To understand the potential effect of traffic, traffic flow was accessed for the city of Graz. The traffic flow data were mainly measured with inductive loop detectors where the detectors measure the change in field when objects pass over them. Once a vehicle drives over a loop sensor, the loop field changes which allows for the detection of the presence of an object (a vehicle). The "Traffic control and street lighting unit of the city of Graz" monitors and records the data at one-minute time frequency and provided data from January 2017 to May 2020 for two sites, namely Don Bosco and Ost.

To determine the lockdown time frame we extracted data from a list of governmental decisions and intervention measures during the lockdown available from ${ }^{2}$ and published in [12]. It consists of country codes, dates and measures countries took to control the pandemic.

\footnotetext{
${ }^{1}$ https://www.umwelt.steiermark.at/cms/ziel/2060750/DE/

2 https://github.com/amel-github/covid19-interventionmeasures
} 


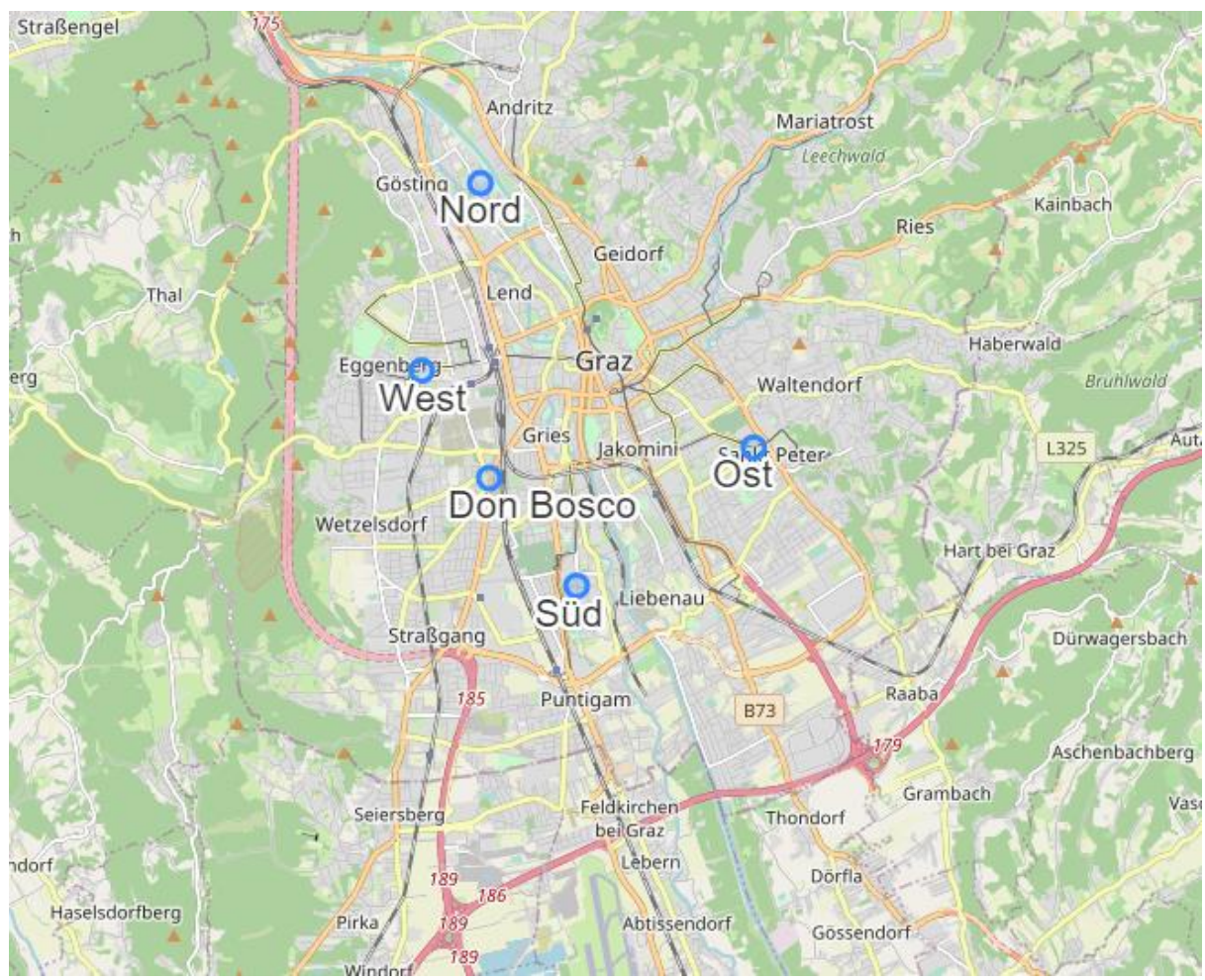

Figure 1. A city map of Graz indicating the five measurement sites: Süd $-47.041692^{\circ} \mathrm{N}$, $15.433078^{\circ} \mathrm{E}$; Nord $-47.09437^{\circ} \mathrm{N}, 15.415122^{\circ} \mathrm{E}$; West $-47.069506^{\circ} \mathrm{N}, 15.403728^{\circ} \mathrm{E}$; Don Bosco $-47.055617^{\circ} \mathrm{N}, 15.416539^{\circ} \mathrm{E}$; Ost $-47.059530^{\circ} \mathrm{N}, 15.466634^{\circ} \mathrm{E}$.

\section{Data processing}

Due to a very high correlation between $\mathrm{PM}_{2.5}$ and $\mathrm{PM}_{10}$ (up to $97 \%$ for Graz South), we did not take $\mathrm{PM}_{2.5}$ into account for this study. The variables in the accompanied dataset are abbreviated as follows: <site>_<pollutant>, i.e. $\mathrm{S}_{-} \mathrm{NO} 2$ would be $\mathrm{NO}_{2}$ measured on the Graz South measurement site. The measurements analyzed were daily means.

Some data points were excluded from the analysis due to the presence of outliers. Observations between $1^{\text {st }}$ and $3^{\text {rd }}$ January each year were excluded due to high $\mathrm{PM}_{10}$ concentrations caused by New Year firework shows. Additionally, $\mathrm{PM}_{10}$ observations between $26^{\text {th }}$ and $30^{\text {th }}$ March, 2020 were excluded because of abnormally high values driven by a Saharan dust event (Federal Office: MeteoSwiss, 2020; Hansen, n.d.; also Supplementary Figure 1). Total oxidant $\left(\mathrm{O}_{\mathrm{x}} ; \mathrm{NO}_{2}+\mathrm{O}_{3}\right)$ was calculated and included in the analysis as an additional pollutant [18]. $\mathrm{O}_{\mathrm{x}}$ was included because it will indicate if the hypothesized changes in $\mathrm{NO}_{2}$ and $\mathrm{O}_{3}$ due to the lockdown measures were caused by a repartitioning of these two species which has consequences for air quality management. 
Table 1. Site description for the air pollution measurement sites, data taken from [15] and http://app.luis.steiermark.at/luft2/suche.php. The number in brackets shows the amount of missing values in data, referring to 2324 values (full number of data entries).

\begin{tabular}{|c|c|c|c|c|c|}
\hline Measurement & Don Bosco (D) & Nord $(\mathbf{N})$ & Ost (O) & Süd (S) & West $(\mathbf{W})$ \\
\hline $\mathrm{O}_{3}\left[\mu \mathrm{g} / \mathrm{m}^{3}\right]$ & & $x(23)$ & & $\mathrm{x}(39)$ & \\
\hline $\mathbf{P M}_{10}\left[\mu \mathrm{g} / \mathrm{m}^{3}\right]$ & $\mathrm{x}(13)$ & $\mathrm{x}(14)$ & $\mathrm{x}(15)$ & $\mathrm{x}(31)$ & $\mathrm{x}(30)$ \\
\hline $\mathrm{NO}_{2}\left[\mu \mathrm{g} / \mathrm{m}^{3}\right]$ & $\mathrm{x}(3)$ & $\mathrm{x}(8)$ & $\mathrm{x}(10)$ & $\mathrm{x}(12)$ & $x(30)$ \\
\hline$\% \mathbf{R H}$ & $\mathrm{x}(0)$ & $\mathrm{x}(12)$ & $\mathrm{x}(1244)$ & $\mathrm{x}(21)$ & $\mathrm{x}(8)$ \\
\hline Air temperature $\left[{ }^{\circ} \mathbf{C}\right]$ & $\mathrm{x}(0)$ & $x(12)$ & $\mathrm{x}(1239)$ & $x(45)$ & $\mathrm{x}(0)$ \\
\hline Precipitation $\left[1 / \mathbf{m}^{2}\right]$ & & $\mathrm{x}(12)$ & & & \\
\hline Wind speed $[\mathrm{m} / \mathrm{s}]$ & & $x(12)$ & $\mathrm{x}(1239)$ & $\mathrm{x}(4)$ & $\mathrm{x}(0)$ \\
\hline Wind direction [Deg] & & $\mathrm{x}(12)$ & $\mathrm{x}(1239)$ & $\mathrm{x}(4)$ & $\mathrm{x}(0)$ \\
\hline Air pressure [mbar] & & $x(12)$ & x (1239) & & \\
\hline
\end{tabular}

Inspired by Grange et al., 2018a; Šimić et al., 2020, we created binary encoded temporal variables for season, month, weekday, and day of year. The other predictive variables were relative humidity, air pressure, air temperature and precipitation, wind direction and wind speed. Variables with $1000+$ missing values were removed, variables with rare missing values were imputed by backfilling. The number of missing value points is provided in Table 1. The processed data consists of 2324 days and 60 variables in total and is provided in table format within a persistent data repository [20]. The traffic data were aggregated to a day frequency and stored as a time series for the two sites $(\mathrm{O}, \mathrm{D})$. The processed traffic data ranges from January 2017 to May 2020.

\section{Exploratory analysis and machine learning methods}

The data was analyzed by means of explorative analysis and regression models. Data exploration was conducted by means of swarm plots (showing distribution of median concentrations in the HLD time frame over the years) and principal component analysis (PCA). For a comprehensive discussion of PCA, readers are advised to consult Abdi and Williams, 2010. We used PCA to inspect any cluster formation among the measurement sites and pollutants. Machine learning was employed to model the expected concentrations (as if no lockdown happened). For machine 
learning one needs a set of predictive variables and a target variable. The methodology follows closely the procedures described previously in [13]. The target variables in the models are the various pollutant concentrations. The predictive variables $(\mathrm{X})$ are weather and environmental conditions as well as temporal variables accompanied by their respective lag-values (values from the previous two days). These predictive variables allow the machine learning model to capture seasonal behavior including activities like industrial production, and traffic (surrogate variables).

The machine learning algorithm used was random forest regression (RF) [22] which has been utilized in a number of previous air pollution models and air quality data analysis studies [13], [19]. The differences between past work and this analysis include: the exclusion of lagvalues of the respective (predicted) pollutant and exclusion of other pollutant concentrations in the respective models. Data processing and model training was conducted with Python. The functions, scripts and libraries are presented in prior work [13], [23].

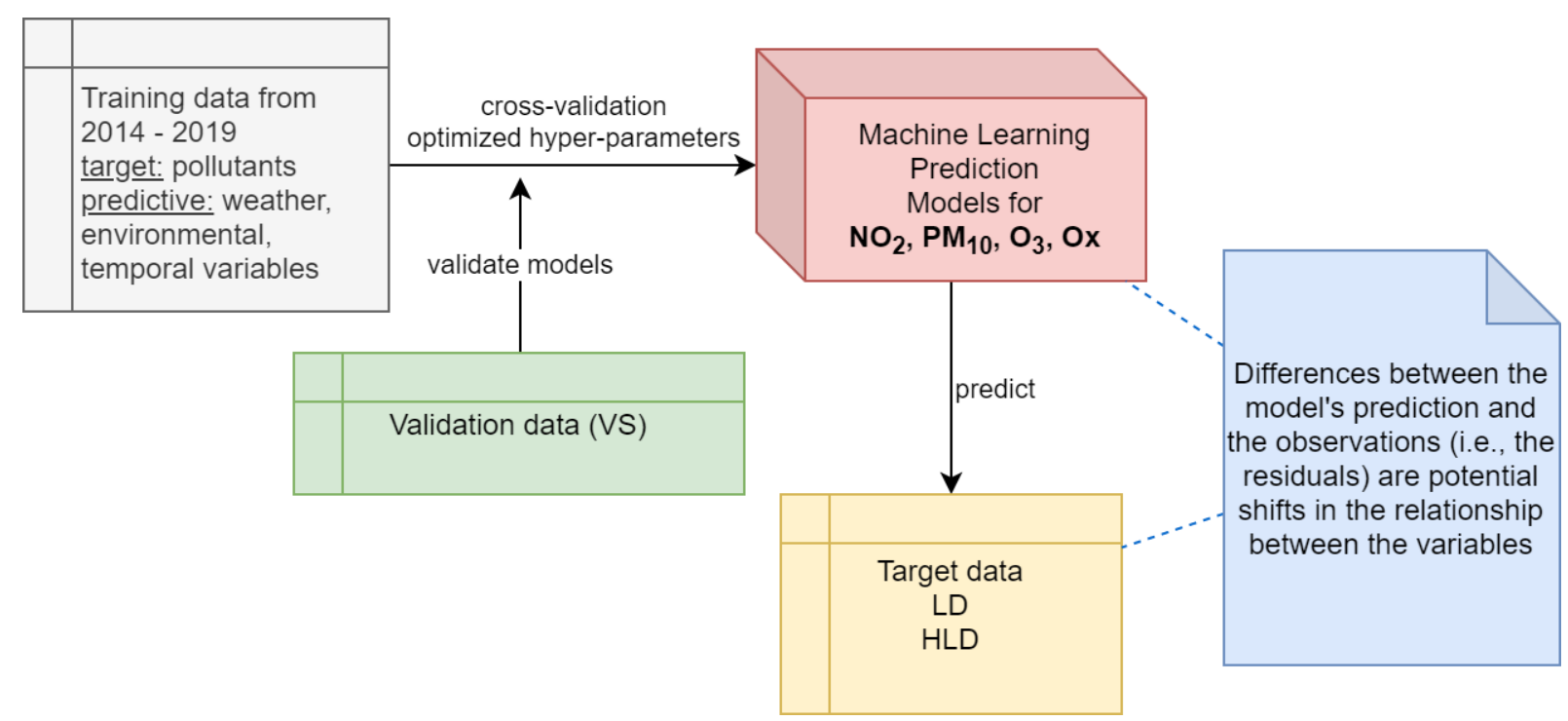

Schema 1: Overview of the study methodology in order to detection changes in the relationships between the (dependent and independent) variables. Table 2 conveys more details on the methodology.

The proposed investigation of the lockdown pollution consists of training RF models for each of the pollutants' concentration (as the target) and observing the difference of predicted to the true values, a concept presented in [24] and depicted in Schema 1. That is, any increase in residuals can be mainly attributed to changes directly or indirectly associated with the lockdown. To achieve models with good generalization we used Bayesian optimization and feature selection by means of permutation importance [23]. The hyperparameter optimization of the RF models was conducted with a 10-fold cross-validation. The period of model training was between $3^{\text {rd }}$ January 2014 and $31^{\text {st }}$ December 2019. The data from 2020 was separated as an external validation set, VS ( $3^{\text {rd }}$ January $2020-10^{\text {th }}$ March 2020), a lockdown set, LD (10 ${ }^{\text {th }}$ March $2020-$ $2^{\text {nd }}$ May 2020) and a hard lockdown set, HLD (20 ${ }^{\text {th }}$ March $2020-14^{\text {th }}$ April 2020) being the time 
frame of interest in this work. The trained models were then used to predict on the VS and the HLD. An overview of the dataset splits together with our expectation is given in Table 2 .

Table 2. An overview of the dataset splits and their utilization in this study.

\begin{tabular}{|c|c|c|c|c|c|}
\hline Name & From & To & Usage & Description & Expectation \\
\hline Training & $\begin{array}{l}3^{\text {rd }} \\
\text { January } \\
2014 \\
\end{array}$ & $\begin{array}{l}31^{\text {st }} \\
\text { December } \\
2019\end{array}$ & $\begin{array}{l}\text { ML model } \\
\text { training }\end{array}$ & $\begin{array}{l}\text { Training data for the ML } \\
\text { models }\end{array}$ & $\begin{array}{l}\text { Training data is sufficient to build a } \\
\text { good predictive model }\end{array}$ \\
\hline $\begin{array}{l}\text { HLD } \\
2014- \\
2019\end{array}$ & $\begin{array}{l}20^{\text {th }} \\
\text { March } \\
20 x x\end{array}$ & $\begin{array}{l}14^{\text {th }} \text { April } \\
20 \mathrm{xx}\end{array}$ & Comparison & $\begin{array}{l}\text { Subset of the training data, } \\
\text { for the relevant time frame } \\
\text { in the years up to } 2019\end{array}$ & $\begin{array}{l}\text { Long term comparison with HDL } \\
2020 \text {, expect a pronounced drop in } \\
\text { pollutant concentration }\end{array}$ \\
\hline $\begin{array}{l}\text { HLD } \\
2019\end{array}$ & $\begin{array}{l}20^{\text {th }} \\
\text { March } \\
2019\end{array}$ & $\begin{array}{l}14 \text { th } \\
\text { April } \\
2019\end{array}$ & Comparison & $\begin{array}{l}\text { Subset of the training data, } \\
\text { for the hard lockdown } \\
\text { time frame the year prior } \\
\text { to lockdown }\end{array}$ & $\begin{array}{l}\text { Short term comparison with HDL } \\
\text { 2020, expected drop in pollutant } \\
\text { concentration (but closer match } \\
\text { than long term) }\end{array}$ \\
\hline VS & $\begin{array}{l}3^{\text {rd }} \\
\text { January } \\
2020\end{array}$ & $\begin{array}{l}10^{\text {th }} \\
\text { March } \\
2020\end{array}$ & Validation & $\begin{array}{l}\text { Validation data set, prior } \\
\text { to the lockdown }\end{array}$ & $\begin{array}{l}\text { Good prediction quality, i.e., } \\
\text { unchanged relationships between } \\
\text { the variables w.r.t. to the training } \\
\text { time frame }\end{array}$ \\
\hline LD & $\begin{array}{l}10^{\text {th }} \\
\text { March } \\
2020 \\
\end{array}$ & $\begin{array}{l}2^{\text {nd }} \text { May } \\
2020\end{array}$ & Prediction & $\begin{array}{l}\text { Entire lockdown phase, } \\
\text { including early measures } \\
\text { and the initial easing phase }\end{array}$ & $\begin{array}{l}\text { Loose fit between model and } \\
\text { observations, due to exogenous } \\
\text { factors, e.g., change in behavior }\end{array}$ \\
\hline HLD & $\begin{array}{l}20^{\text {th }} \\
\text { March } \\
2020\end{array}$ & $\begin{array}{l}14^{\text {th }} \text { April } \\
2020\end{array}$ & Prediction & $\begin{array}{l}\text { Phase of enforced tight } \\
\text { lockdown }\end{array}$ & $\begin{array}{l}\text { Residuals expected to be } \\
\text { contributed to lockdown measures }\end{array}$ \\
\hline
\end{tabular}

\section{Concept validation and method comparison}

The obtained machine learning results, that is, the predicted (expected) pollutant concentrations were compared to the measured (true) values. Our machine learning approach was then evaluated against historical changes in the data (short and long term). To understand the potential causes we evaluated the drop in pollutant concentration against the drop in traffic density. Furthermore, the concentration drops were aggregated to understand the city average concentration drops as an indicator for overall air pollution. 


\section{Results and Discussion}

\section{Explorative analysis}

To gain a better understanding of the relationship between the pollutants we first conducted a principal component analysis (PCA) on the pollutants' concentration data from 2014 to 2020 (Figure 2). The PCA loadings plots show that the distinct measured pollutants group based on their chemical composition, i.e. the same pollutants group together independent of the measurement site. Despite $\mathrm{PM}_{10}$ have a wide range of sources, this pollutant was similar to $\mathrm{NO}_{2}$, indicating that the $\mathrm{PM}_{10}$ concentrations in Graz were primarily sourced from traffic processes during the analysis period. One can observe that in the two groups $\left(\mathrm{PM}_{10}\right.$ and $\left.\mathrm{NO}_{2}\right)$, the northern site $\mathrm{N}$ has lower PC2 loadings. Furthermore, for $\mathrm{NO}_{2}$ and $\mathrm{PM}_{10}, \mathrm{~N}$ is closer to $\mathrm{W}$, which could be explained by both sites being less burdened by traffic emissions. On the contrary for the Don Bosco site (D), $\mathrm{NO}_{2}$ and $\mathrm{PM}_{10}$ are close in the plot, which might be explained by a rather common source, being traffic since it is site with dense traffic. $\mathrm{O}_{3}$ showed distinctly different patterns because $\mathrm{O}_{3}$ is generated by secondary processes and not directly emitted. It can be inferred that the PC2 is more weighted by traffic.

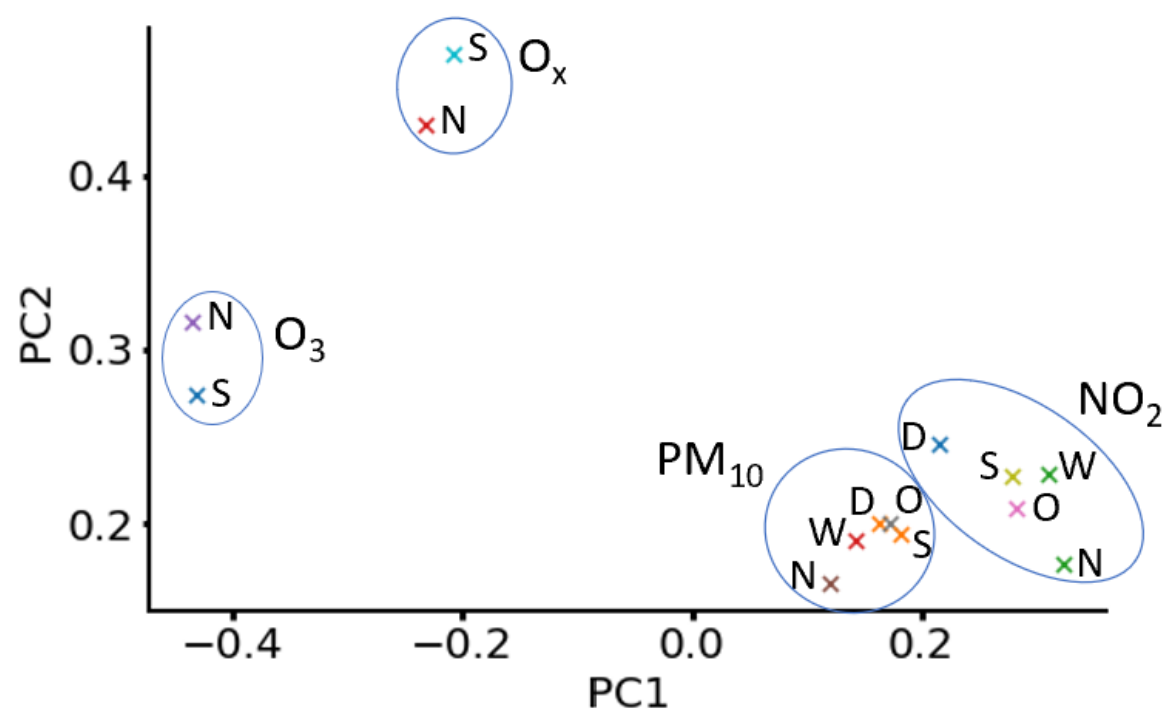

Figure 2. A PCA loadings plot calculated from pollutant concentrations $\left(\mathrm{PM}_{10}, \mathrm{NO}_{2}, \mathrm{O}_{\mathrm{x}}, \mathrm{O}_{3}\right)$ from five sites in (D, N, O, S, W) Graz, Austria, described in Figure 1. The pollutants form groups by means of chemical composition.

To understand the changes during the lockdown, we compared the HLD data in the time frame (20 ${ }^{\text {th }}$ March --14 ${ }^{\text {th }}$ April 2020) to the same time frames during 2014-2019. The swarm plots of the pollutants' concentrations are presented in Figure 3. It can be seen that in the given time frames, particularly for $\mathrm{NO}_{2}$, the concentrations were lower in 2020 as compared to the years 2014 to 2019. $\mathrm{PM}_{10}$ and $\mathrm{O}_{\mathrm{x}}$ do not show clear patterns, whereas $\mathrm{O}_{3}$ appears to have higher average concentration compared to data from the 6 years before. Therefore, a general trend is 
present, traffic-sourced pollutants show concentration drops, while $\mathrm{PM}_{10}$ shows a drop at Don Bosco, which is a traffic-burdened site.
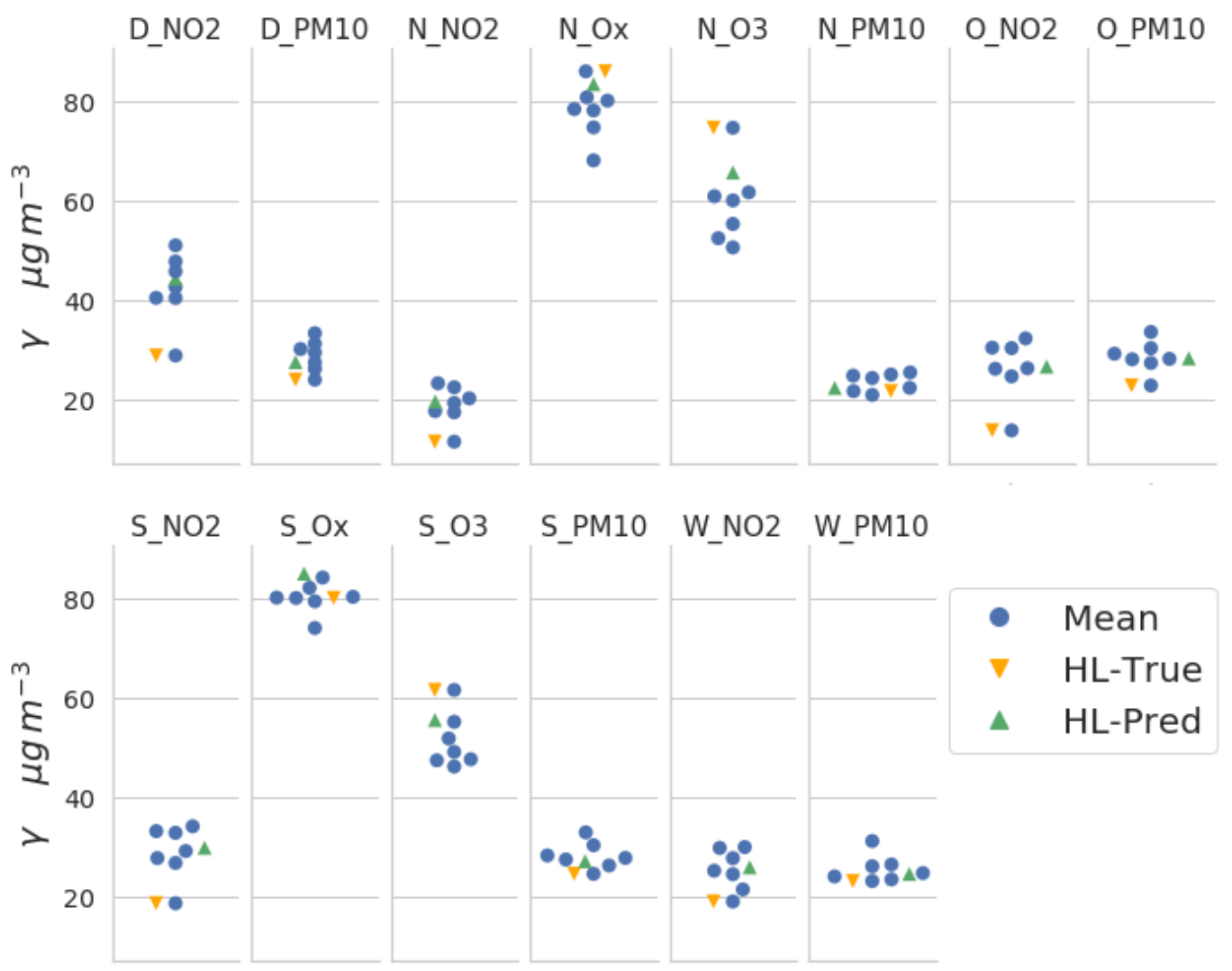

Figure 3. Swarm plots of pollutant concentrations at the five sites during the hard lockdown (HLD) time frame $\left(20^{\text {th }}\right.$ March $-14^{\text {th }}$ April) through years 2014 to 2020 . The 2020 value is colored according to whether it is true or predicted by machine learning (see Machine Learning results section).

\section{Machine learning results}

For understanding the true change in pollution, we trained RF models with pollutants' concentrations as target variables. The optimal/best models (results in Supplementary Table 1) obtained were re-trained on the complete training data sets between 2014 and 2019 and subsequently fitted to data from 2020 (VS, HLD, LD). The results of the RF modelling by means of the coefficient of determination $\left(\mathrm{R}^{2}\right)$, the root mean square error (RMSE) and the normalized RMSE (NRMSE\%) [13] are given in Table 3. Time series plots (as 7-day moving averages) for the predictions (in 2020) and their respective true values for the six pollutants are shown in Figure 4. 
Table 3. $\mathrm{R}^{2}$, RMSE and \%NRMSE value for the external validation and lockdown sets from the best model.

\begin{tabular}{|c|c|c|c|c|c|c|c|c|c|c|c|c|c|c|}
\hline 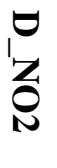 & 当 & $\begin{array}{l}Z \\
\text { Z } \\
\text { Z }\end{array}$ & $\begin{array}{l}Z \\
1 \\
0\end{array}$ & 'ِ & 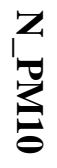 & $\begin{array}{l}0 \\
1 \\
Z \\
0 \\
\end{array}$ & 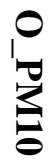 & $\begin{array}{l}\text { L } \\
\text { Z } \\
\text { On }\end{array}$ & $\overbrace{0}^{\infty}$ & مَ & 罗 & $\begin{array}{l}Z \\
\text { Z } \\
\text { ○ }\end{array}$ & 疍 & \\
\hline 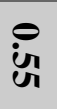 & $\stackrel{0}{0}$ & $\stackrel{\circ}{\dot{a}}$ & in & $\stackrel{0}{\infty}$ & $\stackrel{0}{\stackrel{N}{N}}$ & ir & $\begin{array}{l}0 \\
\stackrel{\mathbb{N}}{N}\end{array}$ & $\stackrel{\circ}{\stackrel{0}{u}}$ & $\begin{array}{l}\dot{0} \\
\dot{0}\end{array}$ & $\underset{\infty}{\infty}$ & $\stackrel{\ominus}{\beth}$ & $\stackrel{\circ}{\infty}$ & ㅇ. & 级 \\
\hline U্র & $\begin{array}{l}\tilde{a} \\
\text { No }\end{array}$ & $\underset{v}{i n}$ & $\begin{array}{l}\vec{N} \\
\frac{\mathrm{a}}{a}\end{array}$ & $\stackrel{N}{\dot{A}}$ & $\begin{array}{l}N \\
\infty \\
\infty\end{array}$ & $\stackrel{N}{N}$ & $\begin{array}{l}\infty \\
\infty \\
\infty\end{array}$ & $\begin{array}{l}\stackrel{N}{\circ} \\
\stackrel{\circ}{\circ}\end{array}$ & $\frac{N}{\frac{N}{a}}$ & $\underset{\omega}{\omega}$ & $\stackrel{N}{\circ}$ & $\begin{array}{l}\omega \\
\dot{ \pm}\end{array}$ & $\stackrel{N}{0}$ & 纪 \\
\hline$\stackrel{+}{\stackrel{\phi}{\phi}}$ & $\begin{array}{l}\text { No } \\
\dot{\omega}\end{array}$ & $\begin{array}{l}\text { yூ } \\
\infty \\
0\end{array}$ & $\begin{array}{l}\infty \\
\dot{6}\end{array}$ & $\stackrel{\overrightarrow{+}}{0}$ & $\begin{array}{l}\text { N } \\
\text { హั }\end{array}$ & $\stackrel{\infty}{\circ}$ & $\underset{v}{w}$ & $\begin{array}{l}\tilde{w} \\
\dot{w}\end{array}$ & $\dot{\infty}_{\infty}^{\omega}$ & $\underset{\omega}{\omega}$ & $\begin{array}{l}\infty \\
\stackrel{\infty}{\sigma}\end{array}$ & $\begin{array}{l}\omega \\
\infty \\
\dot{\omega}\end{array}$ & $\begin{array}{l}N \\
\infty \\
i\end{array}$ & 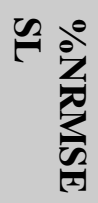 \\
\hline 禹 & $\begin{array}{l}\text { U్ } \\
\text { ¿ }\end{array}$ & $\frac{\infty}{i}$ & $\stackrel{V}{V}$ & $\vec{\omega}$ & $\begin{array}{l}\stackrel{w}{\rho} \\
\dot{u}\end{array}$ & 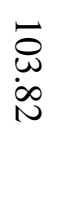 & $\begin{array}{l}\text { wa } \\
\text { ô }\end{array}$ & $\begin{array}{l}\infty \\
\dot{\alpha} \\
\alpha\end{array}$ & $\stackrel{\infty}{\infty}$ & $\bar{\omega}_{0}^{\bar{\omega}}$ & $\underset{\omega}{\omega}$ & $\begin{array}{l}\vec{t} \\
\text { iv }\end{array}$ & $\underset{\infty}{\infty}$ & 四 \\
\hline ì & $\stackrel{0}{\circ}$ & in & $\dot{\sigma}$ & $\ddot{\ddot{\alpha}}$ & $\dot{8}$ & $\dot{\mathrm{j}}$ & $\vec{\omega}$ & ì & テ & 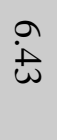 & $\underset{\text { in }}{\infty}$ & $\stackrel{\vec{\sim}}{\not}$ & $\stackrel{\infty}{=}$ & 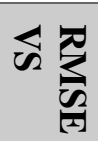 \\
\hline$\underset{+\infty}{+\infty}$ & $\stackrel{N}{N}$ & $\underset{\omega}{\infty}$ & $\forall$ & $\underset{\infty}{\infty}$ & $\underset{\omega}{u}$ & $\stackrel{\tilde{\omega}}{\omega}$ & $\stackrel{\infty}{\text { i }}$ & రి & $\underset{\omega}{\tilde{\omega}}$ & $\begin{array}{l}0 \\
\pm \\
\pm\end{array}$ & $\dot{a}$ & نํㅜ & $\stackrel{\text { ì }}{\text { d }}$ & $\stackrel{\mathscr{2}}{\pi}$ \\
\hline 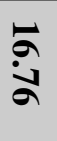 & $\infty$ & $\begin{array}{l}0 \\
\text { un }\end{array}$ & $\stackrel{9}{=}$ & $\underset{\infty}{\infty}$ & ir & $\underset{\infty}{\stackrel{\phi}{\infty}}$ & $\stackrel{\infty}{\not}$ & $\vec{n}$ & ĭ & $\begin{array}{l}\infty \\
\ddot{\alpha}\end{array}$ & $\stackrel{\infty}{\sigma}$ & 疋 & $\dot{V}$ & 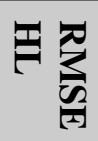 \\
\hline $\mathscr{\infty}_{\infty}$ & $\begin{array}{l}N \\
\text { in } \\
\infty\end{array}$ & $\begin{array}{l}\text { No } \\
\text { ᄋ̊ }\end{array}$ & $\begin{array}{l}\infty \\
\dot{\omega}\end{array}$ & $\begin{array}{l}+\infty \\
9 \\
9\end{array}$ & $\stackrel{N}{\stackrel{O}{\beth}}$ & $\stackrel{N}{\omega}$ & $\underset{\sim}{\sim}$ & $\begin{array}{l}\text { å } \\
\text { in }\end{array}$ & $\stackrel{a}{a}$ & $\begin{array}{l}\omega \\
\dot{\omega}\end{array}$ & $\begin{array}{l}\text { Na } \\
a \\
a\end{array}$ & $\begin{array}{l}N \\
\text { U }\end{array}$ & $\stackrel{N}{\omega}$ & 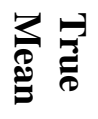 \\
\hline$\stackrel{\infty}{\infty}$ & $\underset{\infty}{\searrow}$ & $\underset{\omega}{\omega}$ & 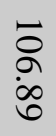 & $\stackrel{\omega}{\omega}$ & $\begin{array}{l}\hat{n} \\
\dot{y}\end{array}$ & $\begin{array}{l}u^{\prime} \\
\stackrel{D}{+}\end{array}$ & 巨 & ب̂̀ & $\begin{array}{l}\text { ㅁ } \\
\text { ป }\end{array}$ & $\stackrel{\infty}{\stackrel{\infty}{\omega}}$ & $\begin{array}{l}\vec{\infty} \\
\text { iు }\end{array}$ & 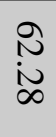 & $\begin{array}{l}\hat{0} \\
\stackrel{ \pm}{y}\end{array}$ & 当 \\
\hline$\stackrel{\infty}{\stackrel{N}{N}}$ & $\hat{\omega}$ & $\dot{\vec{D}}_{\bar{\nabla}}$ & $\underset{+}{\stackrel{\omega}{+}}$ & $\begin{array}{l}\omega \\
\dot{\phi}\end{array}$ & $\ddot{a}$ & $\vec{b}$ & in & $\stackrel{N}{N}$ & $\begin{array}{l}\infty \\
\infty \\
9\end{array}$ & $\dot{\infty}$ & bे & $\underset{\omega}{\omega}$ & $u_{1}^{n}$ & 当 \\
\hline
\end{tabular}



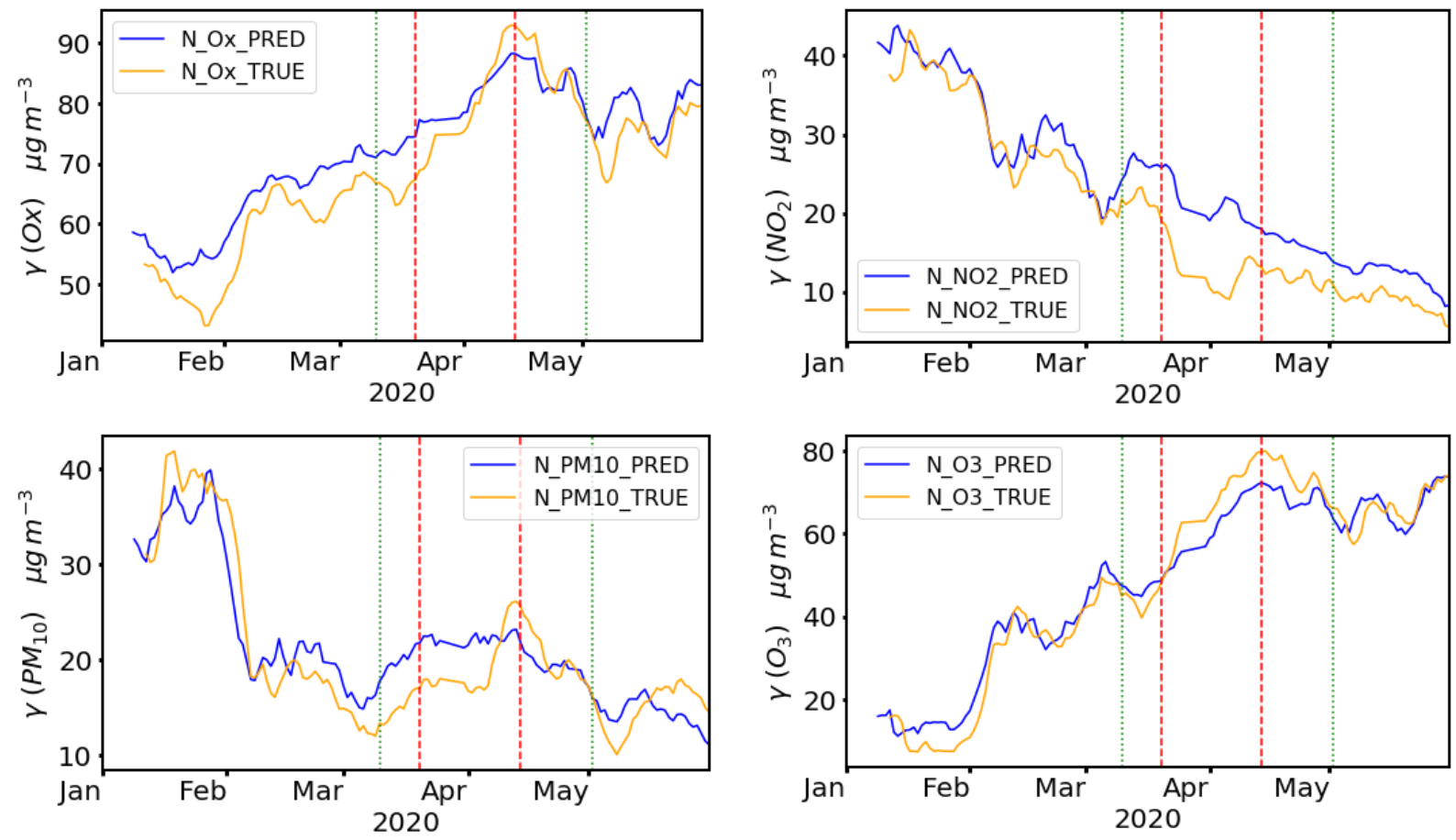

Figure 4. Time series plots for four pollutants' concentrations measured at Graz Nord (N). Orange line (measured) is compared to their predicted values (blue). The plots present a 7day moving average (for better visibility) for the data in 2020. Prior to the green line is the validation set ( $3^{\text {rd }}$ January $2020-10^{\text {th }}$ March 2020). The green dashed lines show the LD time frame $\left(10^{\text {th }}\right.$ March $2020-2^{\text {nd }}$ May 2020) and red dashed lines show the HLD time frame (20 ${ }^{\text {th }}$ March 2020-03-20 $-14^{\text {th }}$ April 2020). Top left is $\mathrm{O}_{x}$, top right is $\mathrm{NO}_{2}$, bottom left is $\mathrm{PM}_{10}$ and bottom right $\mathrm{O}_{3}$. Additional plots are provided in Supplementary Figure 2.

Results from Table 3 and Figures 4 show that for the validation period (VS), the models' prediction quality by means of \%NRMSE declines on average in following order $\mathrm{O}_{\mathrm{x}}<\mathrm{NO}_{2}<\mathrm{O}_{3}$ $<\mathrm{PM}_{10}$, while for the $\mathrm{R}^{2}$ score the prediction declines as follows $\mathrm{O}_{\mathrm{x}}<\mathrm{NO}_{2}<\mathrm{O}_{3}<\mathrm{PM}_{10}$. A number of additional processes such as long-range transport and secondary generation generally drives PM concentrations and these processes are not as relevant to the other gaseous pollutants analyzed here [25], [26]. This increased complication is likely the reason for decreased model performance for the $\mathrm{PM}_{10}$ pollutant.

$\mathrm{NO}_{2}$ and $\mathrm{O}_{3}$ have reasonable prediction performance (validation set), i.e., $\mathrm{O}_{3}$ has $\mathrm{R}^{2}$ scores $0.84(\mathrm{~N})$ and $0.87(\mathrm{~S})$, while $\mathrm{NO}_{2}$ has $\mathrm{R}^{2}$ scores as high as $0.81(\mathrm{~W})$ and $0.76(\mathrm{~N})$ with lower scores for the traffic-loaded sites $(\mathrm{S}-0.45, \mathrm{O}-0.50, \mathrm{D}-0.55)$. A similar pattern appears with $\mathrm{PM}_{10}$ where the lower $\mathrm{R}^{2}$ scores are related to traffic-loaded sites $(\mathrm{O}-0.42, \mathrm{D}-0.61)$. Better scores were achieved at less traffic-loaded sites $(\mathrm{W}-0.66, \mathrm{~N}-0.72)$ and $\mathrm{S}-0.71$. These results overall suggest that the concept of using ML models can support understanding the true pollution.

For the $\mathrm{PM}_{10}$ and $\mathrm{NO}_{2}$ pollutants, the models show concentration reductions (Figure 4 and Supplementary Figure 2) where the observed concentrations were lower than those which were predicted by the RF models. $\mathrm{O}_{3}$ showed the opposite behavior where observed concentrations 
were higher than those predicted. The increases in $\mathrm{O}_{3}$ concentrations can be explained by a reduction of the $\mathrm{NO}^{-} \mathrm{O}_{3}$ titration cycle when $\mathrm{NO}_{\mathrm{x}}$ emissions (and concentrations) were low during the lockdown period.

When comparing the ratios of \%NMRSE VS to \%NMRSE HLD (our proposed indicator for true pollution difference), one can see the largest ratios with $\mathrm{NO}_{2}$ across the sites (2.77-3.98) meaning that they show the largest error in predicted (expected) vs true (measured) concentrations during the lockdown. The ratio is on average lower with $\mathrm{O}_{3}(0.41-0.56)$. The inverse results are due to a concentration rise instead of a concentration drop. $\mathrm{O}_{\mathrm{x}}$ shows a less clear pattern; underprediction for North and overprediction for South (Supplementary Figure 2). With $\mathrm{PM}_{10}$ the ML models suggest that the HLD and VS errors (0.95-1.36) do not deviate largely from each other, pointing to $\mathrm{PM}_{10}$ not being largely affected by the lockdown. Also, there is a period of unexpected high $\mathrm{PM}_{10}$ at the end of HLD which we attribute to lockdown fatigue. Regarding the sites, one can see the largest ratios across pollutants (\%NMRSE VS to HLD) are at the East (O) and Don Bosco (D) sites which are more traffic-loaded than others.

\section{Reduction in pollution/Method comparison}

To support the contribution of machine learning in understanding the pollution we present here a method comparison. Pollution during HLD (median 2020) was compared to the respective medians of 2019 and 2014-2019 (i.e. historical comparison) as well as the median of the predicted HLD 2020. The comparison is presented in Figure 5. 


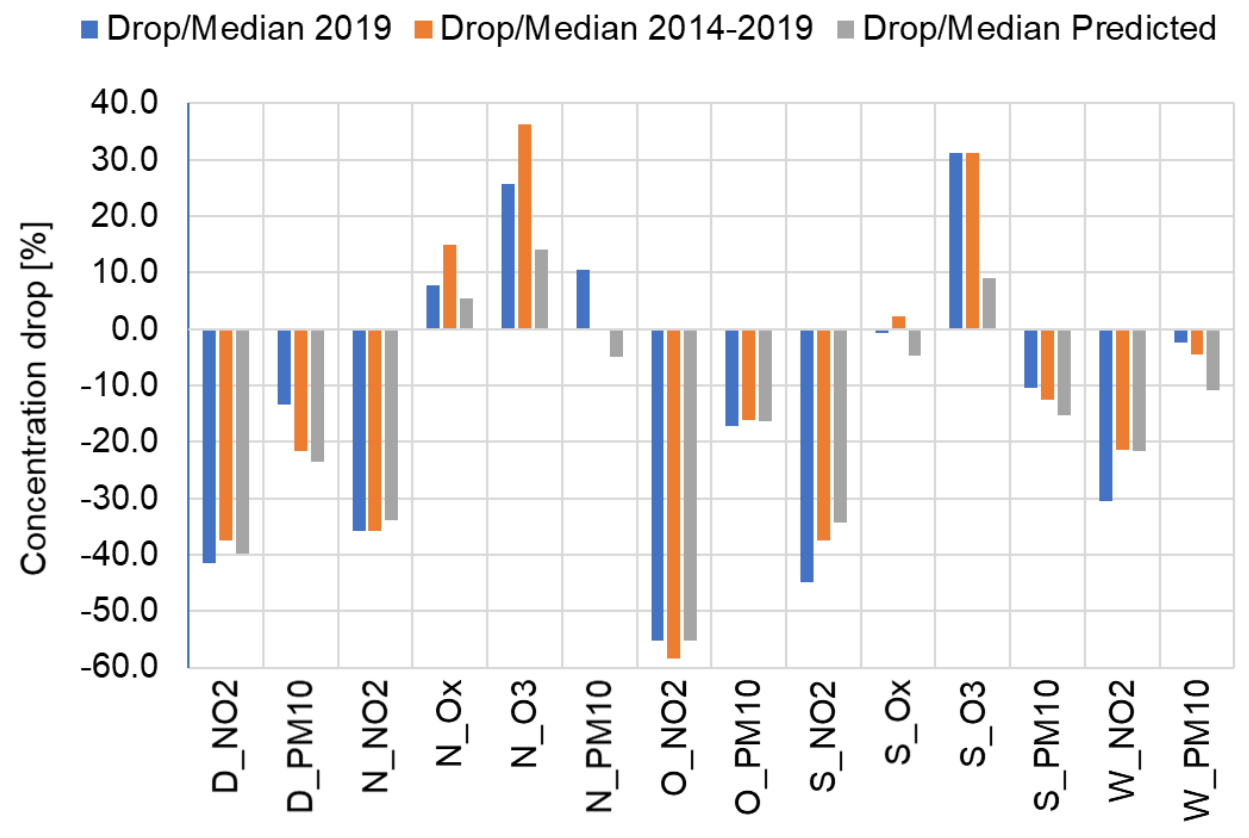

Figure 5. Calculated pollution reduction [\%] from the median HLD values in the time frame (20 ${ }^{\text {th }}$ March $-14^{\text {th }}$ April). The concentration drops i.e. their medians (HLD 2020 to 2019, i.e. short-term) are compared per pollutant to concentration drops (HLD 2020 to 2014-2019, i.e. long-term) and the concentration drops calculated from the predicted values (Data for the plot is provided in Supplementary Table 3).

The results show an overall good agreement for change in pollution of HLD 2020 referred to 2019 (short-term, in blue) and referred to 2014-2019 (long-term, in orange). Notable exceptions are: N_PM10 which shows an increase of $10.5 \%$ short-term and a $0.2 \%$ reduction long-term and W_NO2 showing a larger concentration drop in the short-term (30.6\%) when compared to long-term (21.4\%). One can also observe generally good agreement when comparing changes referred to 2019 and to the predictions of HLD 2020. Pollutants, where the results disagree (short-term vs predicted) the most are N_PM10, N_Ox, N_O3, S_O3, S_NO2 and $\mathrm{W} \_\mathrm{NO} 2$. For $\mathrm{NO}_{2}$ and $\mathrm{O}_{3}$, where good prediction results were achieved, one can assume that the true pollution change is lower than estimated by comparing it to values from previous years. The agreement between the methods validates the machine learning approach as an alternative for analyzing the pollution drop as no ground truth data are available during the lockdown.

For the pollutants where five measurement sites are available, the median concentration drops were averaged across all measurement sites (D, N, O, S, W) to a "city average concentration drop". When comparing the city average concentration drops for 2020 to the shortterm (vs HLD 2019), long-term (vs HLD 2014-2019) and prediction (i.e. predicted HLD 2020) one can see that for $\mathrm{PM}_{10}$ the ML models show a larger concentration drop whereas for $\mathrm{NO}_{2}$ we see a smaller concentration drop with the ML models (Table 4). 
Table 4. The median pollution reductions averaged across sites (D, N, O, S, W) in 2020 when comparing the HLD median to 2019, to HLD median 2014-2019 and to HLD predicted 2020 in percentage. (Data is provided in Supplementary Table 3)

\begin{tabular}{|lrrr|}
\hline & $\begin{array}{l}\text { City average } \\
\text { conc. drop } \\
\text { vs 2019 }\end{array}$ & $\begin{array}{l}\text { City average } \\
\text { conc. drop } \\
\text { vs 2014-2019 }\end{array}$ & $\begin{array}{l}\text { City average } \\
\text { conc. drop } \\
\text { vs predicted }\end{array}$ \\
\hline $\mathbf{N O}_{2}$ & $\mathbf{- 4 1 . 6 \%}$ & $-38.1 \%$ & $-36.9 \%$ \\
\hline $\mathbf{P M}_{10}$ & $-6.6 \%$ & $-11.0 \%$ & $\mathbf{- 1 4 . 2 \%}$ \\
\hline
\end{tabular}

From the available traffic data, we calculated a reduction in median traffic during HLD 2020 against the same median time frame in 2019 and in 2017-2019 for the measurement sites D and $\mathrm{O}$ that are mainly traffic relevant. The traffic measured at the detector loops at these measurement sites showed a reduction of $45.6 \%$ at $\mathrm{O}$ and $51.6 \%$ respectively $43.9 \%$ at $\mathrm{D}$, see Table 5. This reduction of traffic can be correlated with the massive reduction of $\mathrm{NO}_{2}$ at measurement site D and O, see Figure 5, as traffic is especially one of the main sources of these compounds. In contrast the reduction of $\mathrm{PM}_{10}$ is not as pronounced. This demonstrates that traffic is just one part of the air quality problems concerning $\mathrm{PM}_{10}$. Since also the industry was significantly curtailed in and around Graz, it was expected that $\mathrm{PM}_{10}$ should decrease more strongly. This indicates a wider range of influences on $\mathrm{PM}_{10}$ concentrations, and/or a high lag in the relationships involved in the $\mathrm{PM}_{10}$ related variables, i.e., the duration of the intervention was too short to lead to a significant concentration drop in pollutant.

Table 5. Calculated traffic reduction in 2020 when comparing the HLD median to 2019 and to the 2017-2019 HLD median in percentage.

\begin{tabular}{|lll|} 
Year & $\begin{array}{l}\text { Drop in } \\
\text { traffic } \\
\text { density (D) }\end{array}$ & $\begin{array}{l}\text { Drop in } \\
\text { traffic } \\
\text { density (O) }\end{array}$ \\
\hline Median 2019 & $-51.6 \%$ & $-45.6 \%$ \\
\hline Median 2017-2019 & $-43.9 \%$ & $-45.6 \%$
\end{tabular}




\section{Conclusions}

In this work we have examined air pollution concentrations during the COVID-19 lockdown for the city of Graz, Austria to gain better insights into the relative influences of the observed variables on a wide range of pollutants a historic event in human behavior. Besides using explorative methods, we employed random forest regression to differentiate between predicted (expected) values depending on environmental data (not affected by the lockdown) and the lockdown affected (true) pollution levels.

Our prediction models performed well for a series of pollutants indicating the selection of independent variables (predictors) is sufficient to explain changes in the observations as good generalization was observed for some of the pollutants. For $\mathrm{PM}_{10}$ and $\mathrm{NO}_{2}$, the predicted values were found to be above the measured concentrations during the lockdown. $\mathrm{O}_{3}$ was underpredicted during the lockdown time frame which is expected due to relationship with $\mathrm{NO}_{\mathrm{x}}$ concentrations which were reduced during the lockdown because of much lower traffic volumes and therefore emissions. Our findings show that machine learning is a suitable tool to analyze pollution changes during events such as COVID-19 lockdowns. Although, the expected to true differences in pollutant concentration based on machine learning models showed similar results with regard to the historical comparisons, it was an important technique to employ because it enabled for far more robust comparisons with the observed time series.

Still, additional studies are needed with a wider scope (in terms of different geographical regions, additional possible influencing factors, as well as temporal analysis) to improve model generalization in order to obtain more better estimates of event-based air pollution reductions. 


\section{Declarations}

\section{Funding}

The Know-Center is funded within the Austrian COMET Program - Competence Centers for Excellent Technologies - under the auspices of the Austrian Federal Ministry of Transport, Innovation and Technology, the Austrian Federal Ministry of Economy, Family and Youth and by the State of Styria. COMET is managed by the Austrian Research Promotion Agency FFG. SKG is supported by the Swiss Federal Office for the Environment (FOEN) and by the Natural Environment Research Council (NERC) while holding associate status at the University of York.

\section{Availability of data}

The pollution data used for modelling is published [20]. There is no informed consent for making the traffic data accessible or published due to internal guidelines.

\section{Competing interests}

The authors declare that they have no conflict of interest.

\section{Authors' contributions}

Mario Lovrić - Concept, Machine learning, Writing; Kristina Pavlović - Literature research, Visualization, Data collection and curation; Matej Vuković - Machine learning, Visualization, Writing; Stuart K. Grange - Writing, Interpretation, Revision and editing; Michael Haberl - Data collection and curation, Writing, Interpretation; Roman Kern - Concept, Writing, Supervision, Revision and editing

\section{Acknowledgments}

Not applicable. 


\section{Supplementary material}

Supplementary Figure 1. A time series plot with an observation of a "Saharan dust" event. The plot shows two $\mathrm{PM}_{10}$ sites (Graz South and West) related to a change in wind direction observed at Graz South.

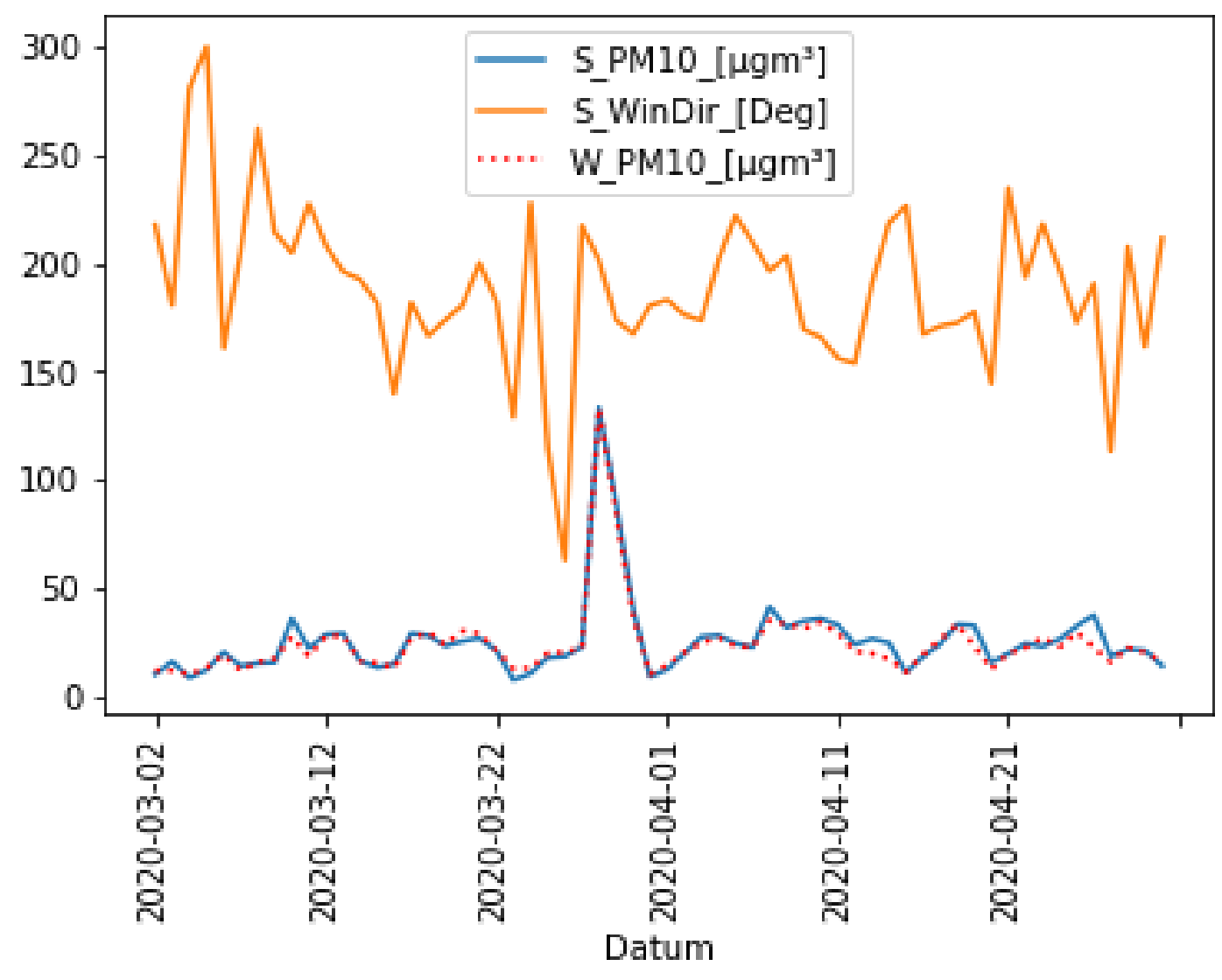


Supplementary Table 1. Hyperparameter optimization results from Random Forest training. The table shows the cross-validation error by means of CV-RMSE, whether the model used feature selection or not and how many features were included in the best model.

\begin{tabular}{llll}
\hline Pollutant & CV-RMSE & Features & $\begin{array}{l}\text { Feature } \\
\text { selection }\end{array}$ \\
\hline D_NO2 & 7.82 & 66 & True \\
\hline D_PM10 & 10.24 & 66 & False \\
\hline N_NO2 & 5.55 & 66 & False \\
\hline N_O3 & 9.52 & 60 & True \\
\hline N_Ox & 8.92 & 66 & False \\
\hline N_PM10 & 8.98 & 66 & False \\
\hline O_NO2 & 6.29 & 64 & True \\
\hline O_PM10 & 10.29 & 66 & False \\
\hline S_NO2 & 7.00 & 60 & True \\
\hline S_O3 & 8.96 & 58 & True \\
\hline S_Ox & 9.25 & 66 & False \\
\hline S_PM10 & 10.44 & 60 & True \\
\hline W_NO2 & 6.36 & 66 & False \\
\hline W_PM10 & 9.63 & 66 & True \\
\hline
\end{tabular}


Supplementary Table 2. Median values for each pollutant throughout years $2014-2020$ during the hard lockdown timeframe $\left(20^{\text {th }}\right.$ March $-14^{\text {th }}$ April). The lowest value per pollutant is marked in bold with an asterisk

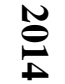

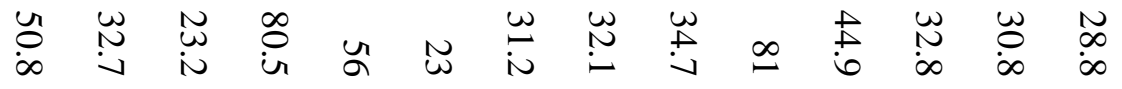

$\stackrel{\text { ê }}{\text { v }}$

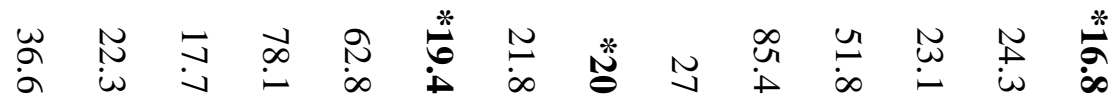

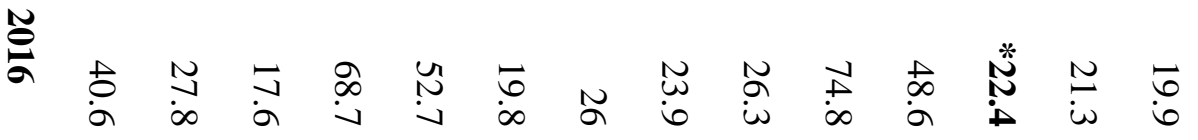

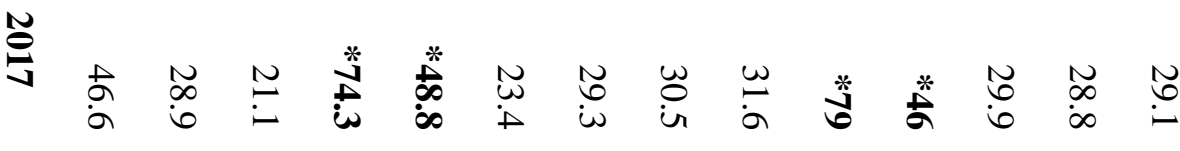

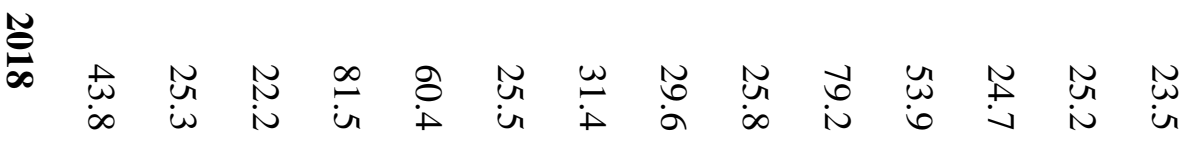

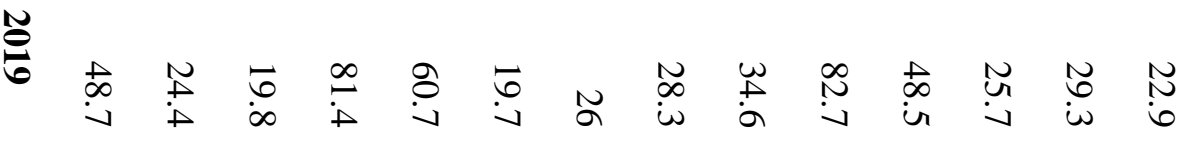

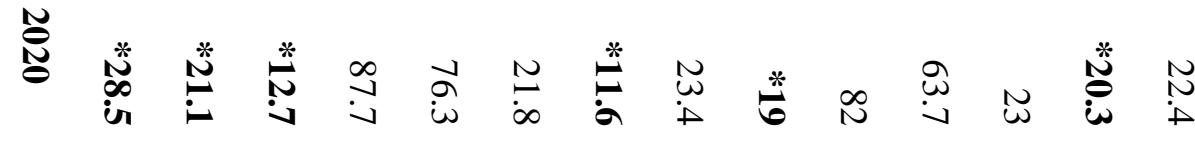

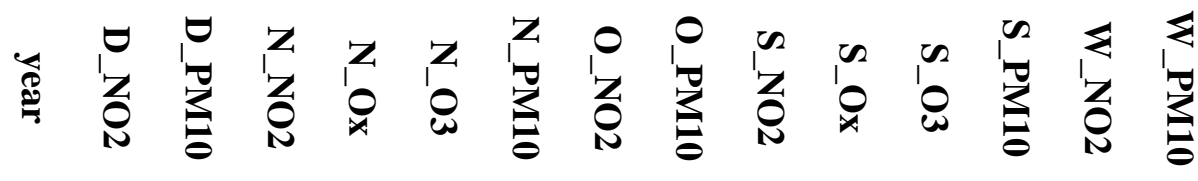



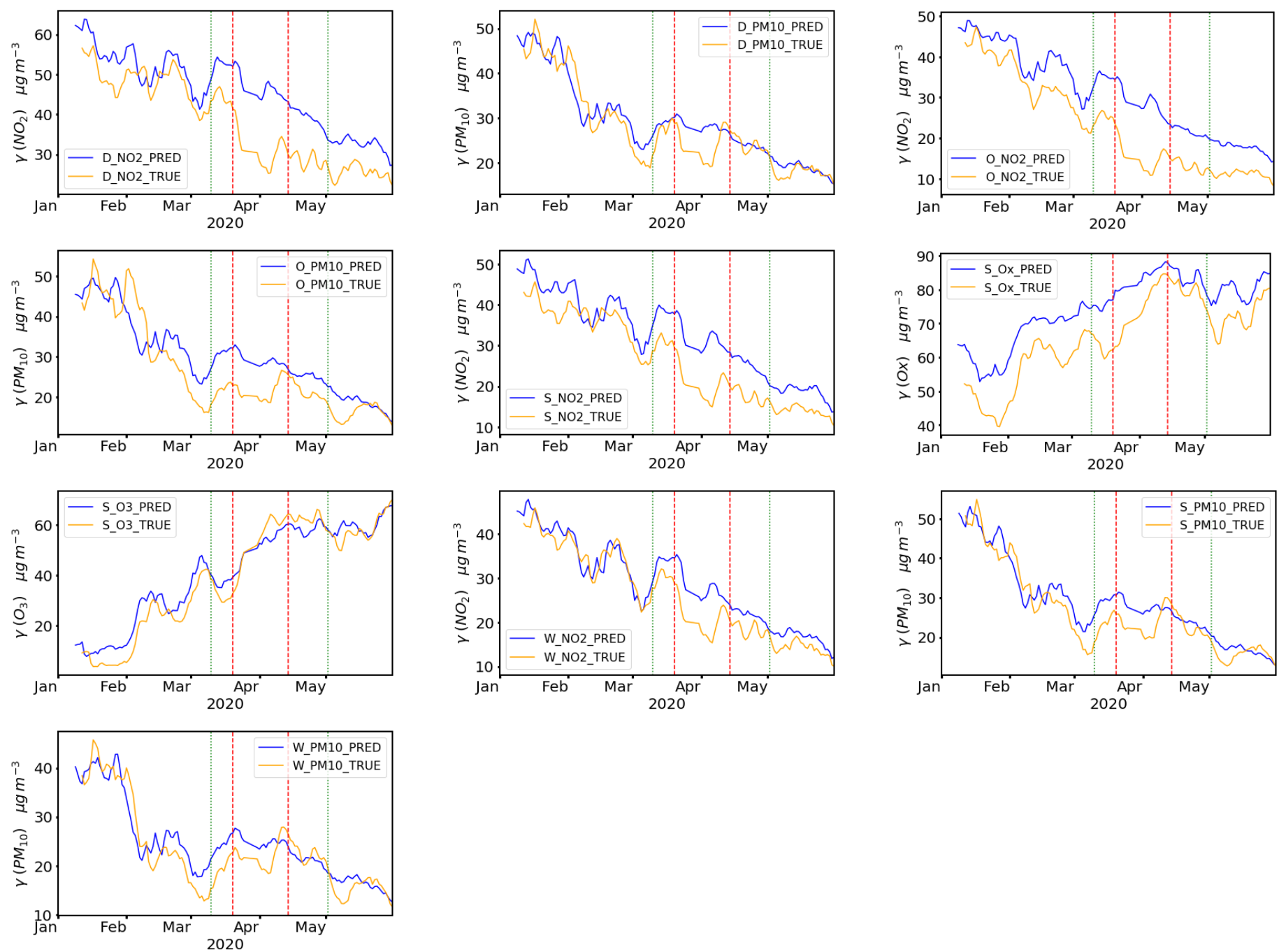

Supplementary Figure 2. Time series plots of exemplary pollutants' concentrations measured at all Graz sites which are not covered by Figure 4 in the Manuscript. Orange line (measured) compared to their predicted values (blue). The plots present a 7-day moving average for the data in 2020. Prior to the green line is the validation set ( $3^{\text {rd }}$ January $2020-10^{\text {th }}$ March 2020). The green dashed lines show the total lockdown time frame $\left(10^{\text {th }}\right.$ March $2020-2^{\text {nd }}$ May $2020)$ and red dashed lines show the hard lockdown time window $\left(20^{\text {th }}\right.$ March $2020-14^{\text {th }}$ April 2020). 


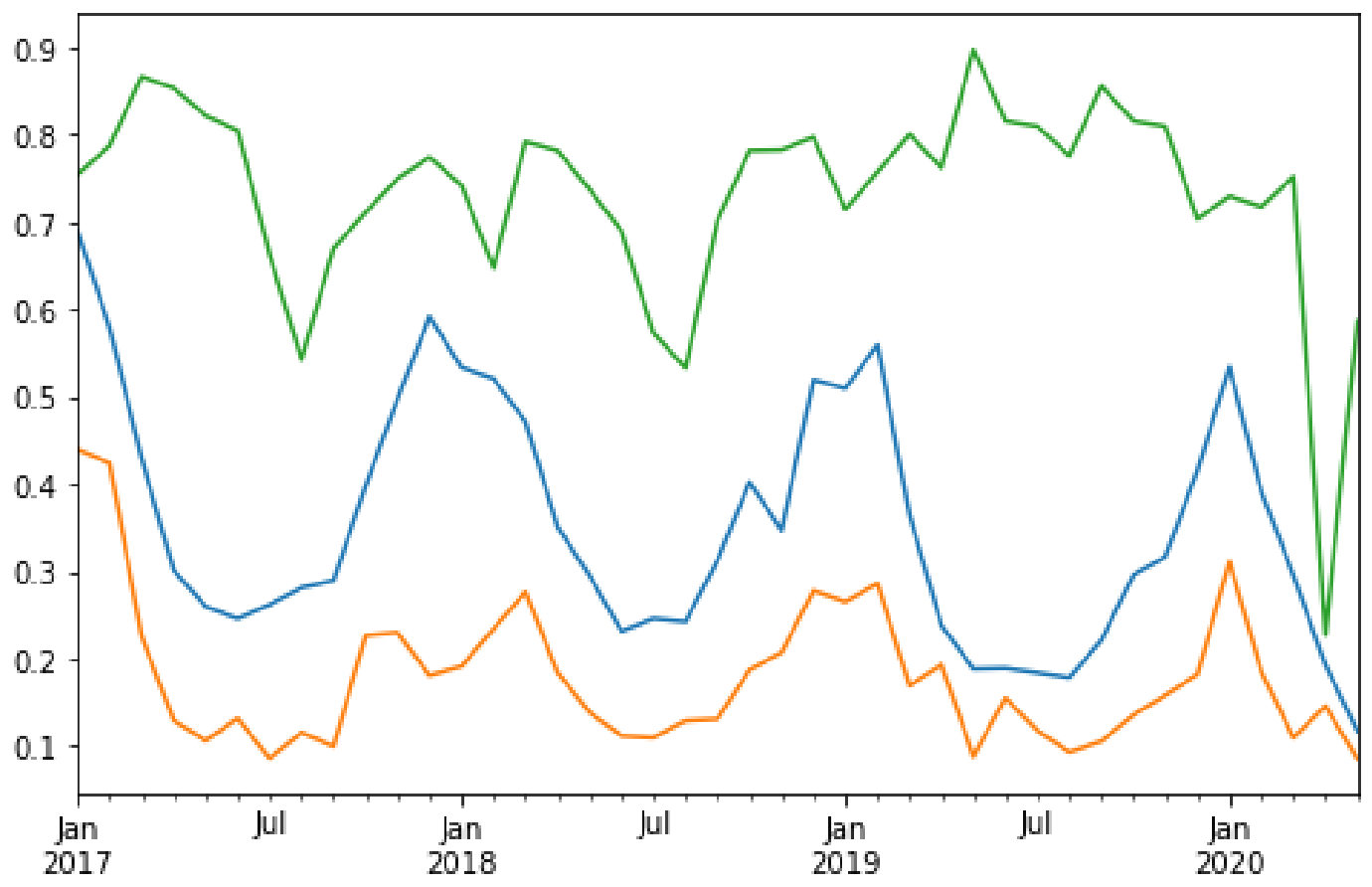

- O_NO2
- O_PM10
- O_traffic

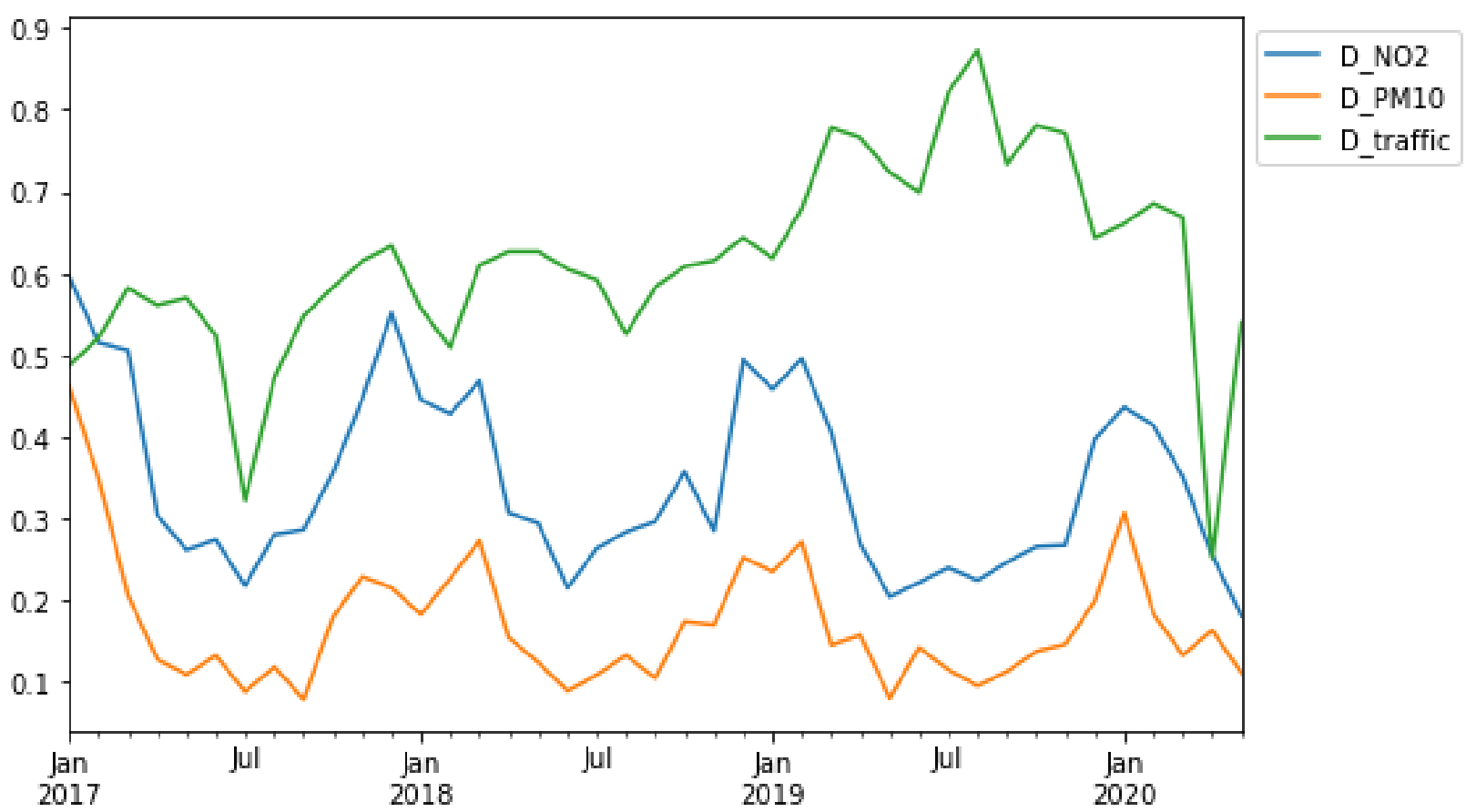

Supplementary Figure 3. Time series plots vs traffic on the two traffic-loaded sites Graz, Don Bosco (top plot) and Graz, Ost (bottom plot). The values are monthly resampled to show a long-term pattern. All values were scaled to a 0-1 (MinMax) scale. 
Supplementary Table 3. Calculated pollution reduction in $\%$ as a concentration drop in the median value based on the hard lockdown time frame $\left(20^{\text {th }}\right.$ March $-14^{\text {th }}$ April $)$. The median of the HLD in 2020 is compared here to median of the same time frame in 2019, 2014-2019 and the predicted values in 2020.

\begin{tabular}{llll}
\hline & $\begin{array}{l}\text { drop/median } \\
\mathbf{2 0 1 9}\end{array}$ & $\begin{array}{l}\text { drop/median } \\
\mathbf{2 0 1 4 - 2 0 1 9}\end{array}$ & $\begin{array}{l}\text { drop/median } \\
\text { predicted }\end{array}$ \\
\hline D_NO2 & $-41.5 \%$ & $-37.4 \%$ & $-39.7 \%$ \\
\hline D_PM10 & $-13.4 \%$ & $-21.6 \%$ & $-23.6 \%$ \\
\hline N_NO2 & $-35.7 \%$ & $-35.7 \%$ & $-33.8 \%$ \\
\hline N_Ox & $7.7 \%$ & $14.9 \%$ & $5.5 \%$ \\
\hline N_O3 & $25.7 \%$ & $36.3 \%$ & $14.1 \%$ \\
\hline N_PM10 & $10.5 \%$ & $-0.2 \%$ & $-4.9 \%$ \\
\hline O_NO2 & $-55.3 \%$ & $-58.4 \%$ & $-55.3 \%$ \\
\hline O_PM10 & $-17.2 \%$ & $-16.2 \%$ & $-16.4 \%$ \\
\hline S_NO2 & $-44.9 \%$ & $-37.4 \%$ & $-34.2 \%$ \\
\hline S_Ox & $-0.8 \%$ & $2.3 \%$ & $-4.7 \%$ \\
\hline S_O3 & $31.3 \%$ & $31.3 \%$ & $9.1 \%$ \\
\hline S_PM10 & $-10.4 \%$ & $-12.6 \%$ & $-15.2 \%$ \\
\hline W_NO2 & $-30.6 \%$ & $-21.4 \%$ & $-21.7 \%$ \\
\hline W_PM10 & $-2.3 \%$ & $-4.6 \%$ & $-10.9 \%$ \\
\hline
\end{tabular}




\section{References}

[1] W. Alabdulmonem, A. Shariq, and Z. Rasheed, "COVID-19: A global public health disaster.," Int. J. Health Sci. (Qassim)., vol. 14, no. 3, pp. 7-8, 2020, Accessed: Jun. 20, 2020. [Online]. Available: http://www.ncbi.nlm.nih.gov/pubmed/32536842.

[2] M. McKee and D. Stuckler, "If the world fails to protect the economy, COVID-19 will damage health not just now but also in the future," Nature Medicine, vol. 26, no. 5. Nature Research, pp. 640-642, May 01, 2020, doi: 10.1038/s41591-020-0863-y.

[3] E. Conticini, B. Frediani, and D. Caro, "Can atmospheric pollution be considered a cofactor in extremely high level of SARS-CoV-2 lethality in Northern Italy?," Environ. Pollut., vol. 261, p. 114465, 2020, doi: 10.1016/j.envpol.2020.114465.

[4] D. Fattorini and F. Regoli, "Role of the chronic air pollution levels in the Covid-19 outbreak risk in Italy," Environ. Pollut., vol. 264, p. 114732, 2020, doi: 10.1016/j.envpol.2020.114732.

[5] Y. Zhu, J. Xie, F. Huang, and L. Cao, "Association between short-term exposure to air pollution and COVID-19 infection: Evidence from China," Sci. Total Environ., vol. 727, no. December 2019, p. 138704, 2020, doi: 10.1016/j.scitotenv.2020.138704.

[6] F. Dutheil, J. S. Baker, and V. Navel, "COVID-19 as a factor influencing air pollution?," Environ. Pollut., vol. 263, pp. 2019-2021, 2020, doi: 10.1016/j.envpol.2020.114466.

[7] R. Bao and A. Zhang, "Does lockdown reduce air pollution? Evidence from 44 cities in northern China," Sci. Total Environ., vol. 731, no. 1954, p. 139052, 2020, doi: 10.1016/j.scitotenv.2020.139052.

[8] P. Krecl, A. C. Targino, G. Y. Oukawa, and R. P. Cassino Junior, "Drop in urban air pollution from COVID-19 pandemic: Policy implications for the megacity of São Paulo," Environ. Pollut., vol. 265, pp. 19-21, 2020, doi: 10.1016/j.envpol.2020.114883.

[9] D. Rodríguez-Urrego and L. Rodríguez-Urrego, "Air quality during the COVID-19: PM2.5 analysis in the 50 most polluted capital cities in the world," Environmental Pollution, vol. 266. Elsevier Ltd, p. 115042, Nov. 01, 2020, doi: 10.1016/j.envpol.2020.115042.

[10] A. Kerimray et al., "Assessing air quality changes in large cities during COVID-19 lockdowns: The impacts of traffic-free urban conditions in Almaty, Kazakhstan," Sci. Total Environ., vol. 730, p. 139179, 2020, doi: 10.1016/j.scitotenv.2020.139179.

[11] L. Li et al., "Air quality changes during the COVID-19 lockdown over the Yangtze River Delta Region: An insight into the impact of human activity pattern changes on air pollution variation," Sci. Total Environ., vol. 732, 2020, doi: 10.1016/j.scitotenv.2020.139282.

[12] A. Desvars-Larrive et al., "A structured open dataset of government interventions in response to COVID-19," Cold Spring Harbor Laboratory Press, May 2020. doi: 10.1101/2020.05.04.20090498.

[13] I. Šimić, M. Lovrić, R. Godec, M. Kröll, and I. Bešlić, “Applying machine learning methods to better understand, model and estimate mass concentrations of traffic-related pollutants at a typical street canyon," Environ. Pollut., vol. 263, p. 114587, Apr. 2020, doi: 10.1016/j.envpol.2020.114587.

[14] M. Hinterhofer, "Anteil der verkehrsbedingten PM10 und PM2,5 Emissionen aus Abrieb und Wiederaufwirbelung an der Feinstaubbelastung in Österreich,” Technische Universität Graz, 2014. 
[15] F. Moser, U. Kleb, and H. Katz, "Statistische Analyse der Luftqualitätin Graz anhand von Feinstaub und Stickstoffdioxid," Graz, 2019.

[16] Federal Office: MeteoSwiss, "Saharan dust events - MeteoSwiss," 2020. https://www.meteoswiss.admin.ch/home/climate/the-climate-of-switzerland/specialties-ofthe-swiss-climate/saharan-dust-events.html (accessed Jul. 31, 2020).

[17] K. Hansen, "More Dust Blows Out from North Africa," 2020. https://www.earthobservatory.nasa.gov/images/146407/more-dust-blows-out-from-northafrica (accessed Jul. 31, 2020).

[18] S. K. Grange and D. C. Carslaw, "Using meteorological normalisation to detect interventions in air quality time series," Sci. Total Environ., vol. 653, pp. 578-588, 2019, doi: 10.1016/j.scitotenv.2018.10.344.

[19] S. K. Grange, D. C. Carslaw, A. C. Lewis, E. Boleti, and C. Hueglin, "Random forest meteorological normalisation models for Swiss PM10 trend analysis," Atmos. Chem. Phys., vol. 18, no. 9, pp. 6223-6239, May 2018, doi: 10.5194/acp-18-6223-2018.

[20] M. Lovrić, K. Pavlović, R. Kern, S. K. Grange, M. Vuković, and M. Haberl, "Air pollution 01.2014 - 05.2020 (including COVID-19 lockdown) data from Graz, Austria,” Jul. 2020, doi: 10.5281/zenodo.3982670.

[21] H. Abdi and L. J. Williams, "Principal component analysis," Wiley Interdisciplinary Reviews: Computational Statistics, vol. 2, no. 4. pp. 433-459, Jul. 2010, doi: 10.1002/wics.101.

[22] L. Breiman, Random Forests, vol. 45, no. 1. 2001, pp. 5-32.

[23] M. Lovrić et al., "Machine learning in prediction of intrinsic aqueous solubility of druglike compounds: generalization, complexity or predictive ability?," chemrxiv, Aug. 2020, doi: 10.26434/chemrxiv.12746948.

[24] M. Lovrić, L. Fadljević, R. Kern, T. Steck, J. Gerdenitsch, and E. Peche, "Prediction of anode lifetime in electro galvanizing lines by big data analysis," 2020, Accessed: Apr. 21, 2020. [Online]. Available:

https://www.researchgate.net/publication/340816111_PREDICTION_OF_ANODE_LIFE_ TIME_IN_ELECTRO_GALVANIZING_LINES_BY_BIG_DATA_ANALYSIS.

[25] S. K. Grange, D. C. Carslaw, A. C. Lewis, E. Boleti, and C. Hueglin, "Random forest meteorological normalisation models for Swiss PM10 trend analysis," Atmos. Chem. Phys., vol. 18, no. 9, pp. 6223-6239, 2018, doi: 10.5194/acp-18-6223-2018.

[26] M. Viana et al., "Source apportionment of particulate matter in Europe: A review of methods and results," Journal of Aerosol Science, vol. 39, no. 10. Elsevier Ltd, pp. 827849, Oct. 01, 2008, doi: 10.1016/j.jaerosci.2008.05.007. 